\section{The mentoring role for DNP projects}

By Ella T. Heitzler, PhD, WHNP-BC, FNP-BC, RNC-OB, and Gina M. Fullbright, DNP, WHNP-BC, RN

he number of Doctor of Nursing Practice (DNP) programs and DNP-prepared nurses across the United States continues to grow. The DNP is a terminal degree in nursing that prepares graduates to practice at the highest level of nursing practice. ${ }^{1}$ DNP-prepared nurses are in the position to lead other healthcare practitioners in collaborative efforts to improve healthcare and health outcomes. The National Association of Nurse Practitioners in Women's Health (NPWH) acknowledges the continuously increasing complexity of healthcare, that women benefit from women's health nurse practitioners (WHNPs) prepared at the highest level, and that DNP education prepares WHNPs to provide healthcare to women while enhancing NP practice. Simply said, “DNP-prepared WHNPs provide a critical interface between practice, research, and policy, with a focus in women's health." ${ }^{2}$

The American Association of Colleges of Nursing (AACN) DNP Essentials support the inclusion of a final scholarly project in DNP programs to demonstrate the application of clinical scholarship. ${ }^{1}$ According to the AACN, DNP projects are neither research dissertations nor simply capstone projects. Rather, a DNP project fulfills many roles. It is typically a required deliverable in a DNP program, a demonstration of how the doctoral competencies have been met, a way to achieve a professional goal, and a way to support the goals of the setting or organization in which the project is implemented. ${ }^{3}$

DNP project format varies across institutions, but the elements of the DNP project are universal: planning, implementation, and evaluation. ${ }^{1}$ Specifically, DNP projects should focus on a change that impacts healthcare outcomes, have a systems or population focus, demonstrate implementation, include sustainability planning, evaluate processes or outcomes, and serve as a foundation for further scholarly practice. ${ }^{1}$ DNP project team members serve as mentors and oversee the DNP project. At a minimum, DNP project teams should consist of the student (or students), a doctoral-prepared faculty member mentor, and a practice mentor. Additional formal or informal mentors and collaborators may be involved in the project as needed. ${ }^{1}$ Regardless of project team composition, DNP students must be guided through their project by experienced collaborative mentors from both their academic program and their practice site/field. ${ }^{3}$

\section{Formal DNP project mentors}

Thoughtful and deliberate mentorship is key to DNP project success. Mentorship can generally be defined as a developmental relationship, both personal and reciprocal, in which an individual with more experience guides, teaches, and sponsors an individual with less experience. ${ }^{4}$ The DNP project mentor at the student's academic institution is a doctoral-prepared member of the faculty who nurtures and shepherds the DNP project from conception through implementation, evaluation, and dissemination. Practice mentors, the second type of formal mentor, are typically content or site experts and are involved in the steps of the project as appropriate with their experience and expertise.

There are many desirable traits of formal DNP project mentors across the cognitive, psychomotor, and affective domains. The cognitive domain includes essential knowledge, whereas the psychomotor domain includes key actions. Effective formal DNP project mentors must combine their knowledge and skills to guide DNP students through their projects. Students typically require guidance in design, implementation, and evaluation. However, students come from various backgrounds and have varying baseline knowledge. Hence, it is essential that mentors assess the knowledge of their students and build on the existing foundation. Project mentors should not only have knowledge of various types of DNP projects and methodologies but also be able to effectively share their knowledge with the student. Communication is therefore critical. Project mentors should be effective verbal and written communicators and possess strong listening skills. Guidance in scholarly writing relevant to the project requires timely, thorough, substantive constructive feedback. ${ }^{5}$ Both project and practice mentors need to have knowledge of, and be committed to adhering to, any applicable project guidelines. ${ }^{5}$

Although practice mentors bring varying expertise and skills to the DNP project team, there are traits that all practice mentors ideally possess. Practice mentors should have a strong knowledge of one or more aspects of the DNP project. Although this often includes an extensive knowledge of the population or implementation site, practice mentors may also have in-depth knowledge about the intervention, evaluation method, or another aspect of the project. Practice mentors should be effective communica- 


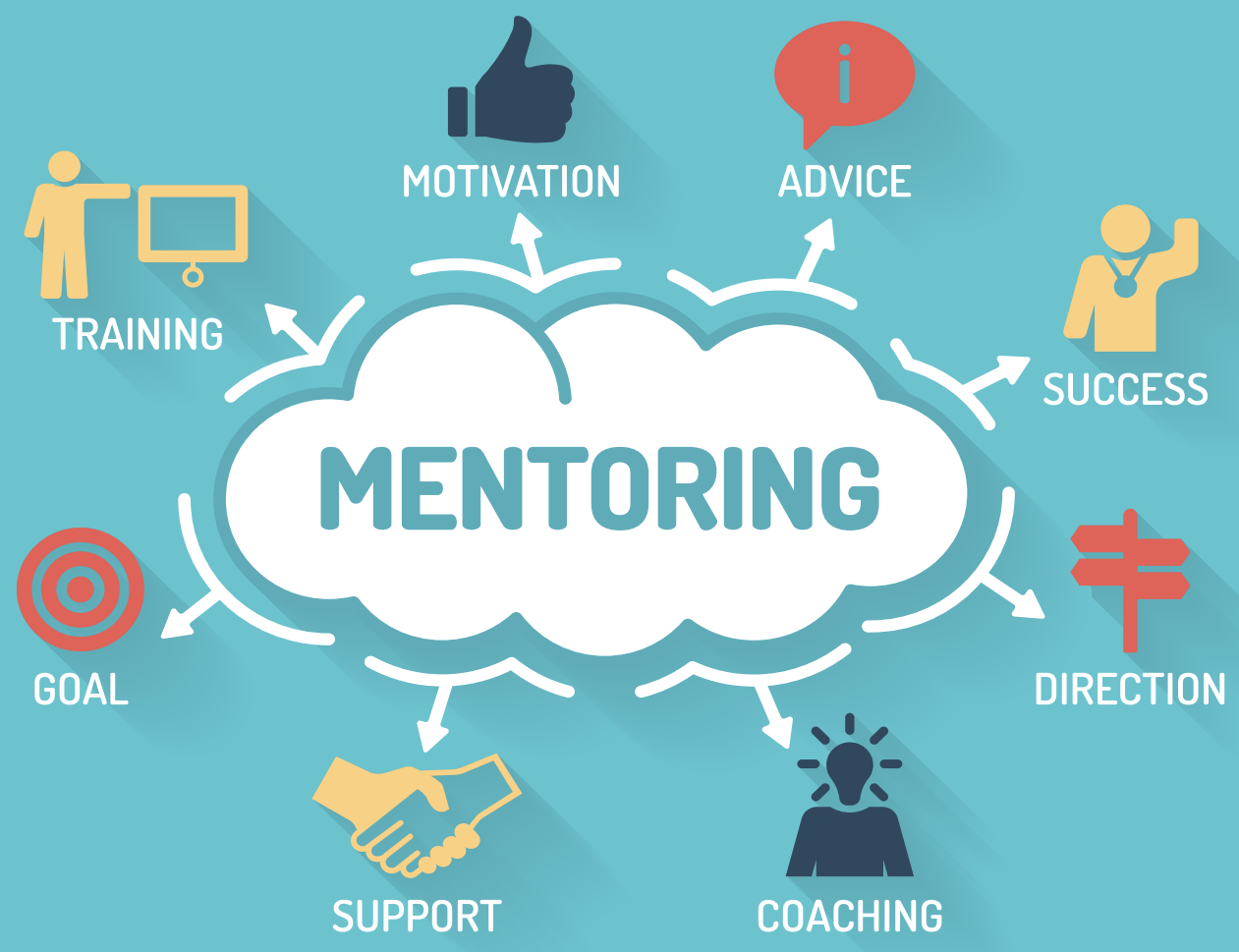

tors, explore the student's interest, and assist the student in establishing a collaborative fit between their interest and the needs of the project site. ${ }^{6}$ Ideally, practice mentors provide organizational context and have influence at the project implementation site, allowing them to aid the student in developing rapport with stakeholders and navigating the project environment. ${ }^{3}$

Unforeseen challenges are often encountered in the planning, implementation, and evaluation of DNP projects and can necessitate change and adaptation. Hurdles in acquiring institutional review board or other required approval, obtaining and maintaining project site support, and recruiting participants, among others, are common. Therefore, project and practice mentors must be flexible and assist students in overcoming challenges. Effective mentors anticipate potential obstacles and work to mitigate both anticipated and unanticipated barriers encountered during the project. Strong mentors balance offering support with challenging students in ways that empower and assist them in growing both personally and professionally.

There are also desirable mentor traits in the affective domain. The affective domain addresses attitudes that are both observable and unseen. Respect, openness, warmth, and a positive outlook help build successful mentoring relationships. ${ }^{4}$ Strong DNP project and practice mentors have the desire to be a mentor and to serve as a role model for others. They respect the students they work with and the practice doctoral degree for nurses in general. ${ }^{5}$ Great mentors come with a positive attitude, are invested in the project and the student's success, value collaboration, and use an individualized approach to mentor the student. ${ }^{5}$ Mentors should also be caring, empathetic, and available to the student. ${ }^{5}$ Time is a precious commodity in both academia and practice, and effective mentoring takes time. Hence, mentors must ensure they have the time, experience, desire, and ability to mentor well.

\section{Informal DNP project mentorship}

One does not have to be a formal member of the DNP project team to impact a student project and its success. Informal mentors, such as stakeholders or others who have been through a similar process, also support a student in their DNP project journey. Stakeholders vary by DNP project topic and setting, but often include patients, healthcare providers, support staff, and administrators at the project site. Many individuals can serve as informal mentors.

Informal mentors play many roles in the DNP project. An informal mentor may serve as a motivator, a participant in the project, an emotional support, or an assistant in the implementation or evaluation process. Informal mentors might also ask thought-provoking questions or provide realistic suggestions to strengthen the project plan. They 


\section{Although the role informal} mentors take varies, there are traits that informal mentors

\section{ideally possess across the}

\section{affective, psychomotor, and cognitive domains.}

may help the student gain the support of others at the implementation site by providing introductions, helping establish rapport, and promoting the project. After all, it is very difficult to implement a change if others are not receptive to the change or the change process.

Although the role informal mentors take varies, there are traits that informal mentors ideally possess across the affective, psychomotor, and cognitive domains. Informal mentors should have positive attitudes and be open to the change process. They should be supportive, caring, dedicated, and respectful of both the student and their project. Each informal mentor brings a unique perspective to the project, and clear communication is key. Informal mentors should share any concerns directly with the DNP student and project team, asking for clarification or guidance rather than undermining the project. Finally, the role of informal mentor may be time consuming and necessitates substantial commitment.

\section{DNP project impact}

Doctor of Nursing Practice students are uniquely poised to impact various aspects of health and healthcare systems through implementation of their DNP project. DNP graduates lead quality improvement initiatives across systems and report that the experience and skills obtained through their projects lend themselves to collaboration and partnerships beyond the practice setting. ${ }^{7}$ Graduates also report they continue to publish and present on the outcomes of their DNP projects to audiences beyond their clinical focus, maximizing impact across the healthcare spectrum. ${ }^{7}$

DNP-prepared nurses are employed in various practice settings throughout the healthcare system and community. DNP-prepared nurses contribute to changes in health policy, clinical practice, complex health systems, population health, evidence-based practice, and academia. ${ }^{8}$ Although the impact of DNP-prepared nurses remains largely unquantifiable, employer survey results note DNP degree holders have a far-reaching positive impact on staff, patient, and organizational outcomes in their roles as advanced practice registered nurses, leaders, administrators, and executives. ${ }^{9}$

\section{Conclusion}

DNP-prepared nurses and their projects have widespread positive impact on health and healthcare systems. Pursuing a DNP degree may not appeal to all nurses, but all nurses can support DNP projects. Practicing clinicians, academics, doctoral-prepared nurses, and other stakeholders can serve as valuable formal and informal mentors for DNP projects. In fact, projects cannot be completed in isolation or without the support of these mentors. DNP project mentorship benefits everyone by continuously propelling healthcare and the nursing profession forward.

\section{Ella T. Heitzler is Assistant Professor and Gina M. Full- bright is adjunct faculty at the Georgetown University School of Nursing and Health Studies in Washington, DC. The authors have no actual or potential conflicts of interest in relation to the contents of this article.}

\section{References}

1. American Association of Colleges of Nursing. The Doctor of Nursing Practice: Current issues and clarifying recommendations. https://www.pncb.org/sites/default/files/2017-02/ AACN_DNP_Recommendations.pdf. August 2015.

2. The National Association of Nurse Practitioners in Women's Health. The Doctor of Nursing Practice for women's health nurse practitioners. 2020. www.npwh.org.

3. Moran K, Burson R, Conrad D. The Doctor of Nursing Practice Project: A Framework for Success, 3rd ed. Burlington, MA: Jones \& Bartlett Learning; 2020.

4. Johnson WB. On Being a Mentor: A Guide for Higher Education Faculty, 2nd ed. New York, NY: Taylor \& Francis; 2016.

5. Prol L. Passion and ability: mentoring in a doctorate of nursing practice programme. Nurse Educ Pract. 2020;(43):102715.

6. Staffileno BA, Murphy MP, Hinch B, Carlosn E. Exploring the Doctor of Nursing Practice project facilitator/mentor role. Nurs Outlook. 2019;67:433-440.

7. Pritham UA, White P. Assessing DNP impact: using program evaluations to capture healthcare system change. Nurse Pract. 2016;41(4):44-53.

8. Edwards NE, Coddington J, Erler C, Kirkpatrick J. The impact of the role of Doctor of Nursing Practice nurses on healthcare and leadership. Med Res Arch. 2018;6(4).

9. Beeber AS, Palmer C, Waldrop J, et al. The role of Doctor of Nursing Practice-prepared nurses in practice settings. Nurs Outlook. 2019;67(4):354-364. 